\title{
Tratamiento moderno de la hemofilia y el desarrollo de terapias innovadoras.
}

\author{
Arlette Rui:-Sáeঞ \\ Centro Nacional de Hemofilia. Departamento de Investigación y Docencia, \\ Banco Municipal de Sangre, Caracas, Venezuela.
}

Palabras clave: hemofilia; tratamiento; innovaciones; terapia génica.

Resumen. La hemofilia es una enfermedad hemorrágica resultante de mutaciones en el gen del factor VIII (F8) de la coagulación en el caso de la hemofilia A o en el gen del factor IX (F9) en el caso de la hemofilia B, siendo ambas formas indistinguibles clínicamente. El fenotipo clínico usualmente refleja la actividad del factor en plasma y la principal complicación del tratamiento es el desarrollo de aloanticuerpos neutralizantes. El tratamiento moderno de la hemofilia comienza a despuntarse en la década de 1970 con la disponibilidad de concentrados de factores de la coagulación de origen plasmático, el inicio de programas de profilaxis y el manejo multidisciplinario de la condición. Posteriormente, la producción de concentrados seguros, debidamente inactivados o de origen recombinante, facilitó la individualización de la terapia y el desarrollo de los agentes baipás mejoró el tratamiento de pacientes con inhibidores. Para todas esas opciones, la gran limitante ha sido la necesidad de frecuentes infusiones endovenosas por un tiempo indefinido. La biotecnología ha permitido el desarrollo de concentrados de factor VIII y IX de vida media plasmática extendida y a la producción de terapias novedosas, diferentes a la terapia de remplazo, que mejoran la coagulación o inhiben las vías anticoagulantes naturales. Por último, los progresos en la terapia génica como potencial cura de la condición generan grandes expectativas. Si bien estos avances ofrecen alternativas terapéuticas para pacientes con o sin inhibidores, aún están por definirse aspectos relacionados a sus indicaciones, monitorización y seguridad a corto y largo plazo.

\footnotetext{
Autor de correspondencia: Arlette Ruiz-Sáez. Centro Nacional de Hemofilia. Departamento de Investigación y Docencia, Banco Municipal de Sangre, Caracas, Venezuela. Tel + 58212 5628107-+58 412 2239926. Correo electrónico: arletteruizsaez@gmail.com
} 


\title{
Modern treatment of hemophilia and development of innovatives therapies.
}

\author{
Invest Clin 2021; 62 (1): 73-95
}

Key words: hemophilia; treatment; innovations; gene therapy.

\begin{abstract}
Congenital hemophilia is a bleeding disorder caused by mutations in the F8 or F9 clotting factor genes in hemophilia A or in hemophilia B, respectively. The two types of hemophilia are clinically indistinguishable. The clinical phenotype is usually associated with the residual factor level and the main complication of the treatment is the appearance of neutralizing alloantibodies. The modern management of hemophilia began in the 1970s, with the availability of plasma-derived concentrates of coagulation factors, the implementation of prophylaxis programs and a multidisciplinary comprehensive care approach. Later, the therapeutic production of safer virally inactivated and recombinant coagulation factors, allowed for an individualized approach, and the production of bypass agents improved the management of patients with inhibitors. For all these options, the greatest challenge has been the need of life-long frequent intravenous infusions. Biotechnology has made possible the development of Factor VIII and IX concentrates with an extended halflife, as well as the production of therapies other than replacement therapy. These innovations improve clotting or inhibit the natural anticlotting ways. Finally, advances in gene therapy as a potential cure, are generating great expectations. All these advances have offered therapeutic alternatives for hemophilia patients with and without inhibitors. However, long-term safety and monitoring are important issues to be defined.
\end{abstract}

Recibido: 23-09-2020 Aceptado: 08-10-2020

\section{INTRODUCCIÓN}

La hemofilia es una enfermedad hemorrágica de naturaleza congénita ocasionada por la deficiencia del factor VIII de la coagulación en el caso de la hemofilia A (HA) o del factor IX denominada hemofilia B (HB), ambas formas indistinguibles clínicamente. Es un trastorno de origen genético resultante de variantes patológicas en los genes del F8 o del F9 de la coagulación respectivamente. Ambos genes son pronos a nuevas mutaciones, lo cual puede explicar que el 30-50\% de los casos no tengan historia familiar de hemofilia y sean el resultado de variantes genéticas espontáneas (1).
Se transmite de forma recesiva ligada al cromosoma $\mathrm{X}$, afectando mayoritariamente a varones quienes heredan un cromosoma $\mathrm{X}$ materno con la mutación. Las mujeres con hemofilia (FVIII o FIX $<40 \mathrm{UI} / \mathrm{dL}$ ), son muy poco frecuentes y pueden ser el resultado de afectación de ambos cromosomas $\mathrm{X}$ o de la herencia de un cromosoma afectado con el otro cromosoma inactivo.

Las alteraciones moleculares condicionan los niveles de factor en el plasma y por ende la gravedad de la enfermedad. Ambos tipos de hemofilia según el nivel de factor circulante en plasma y se subdividen en severa o grave $(<1 \mathrm{UI} / \mathrm{dL})$, moderada $(1-5 \mathrm{UI} /$ $\mathrm{dL})$ o leve $(5-40 \mathrm{UI} / \mathrm{dL})$ (2). La manifesta- 
ción clínica más frecuentes es la hemartrosis (70-80\% de los sangrados), seguida del sangrado muscular o en espacios cerrados como el sistema nervioso central progresando a la artropatía, la discapacidad o la muerte, en caso de no recibir el tratamiento adecuado en forma temprana (3).

Las mejores estimaciones sobre la prevalencia de la hemofilia a nivel mundial se basan en los datos aportados por los registros nacionales y en las encuestas anuales recopiladas por la Federación Mundial de la Hemofilia (FMH). La HA representa el 80-85\% de los casos, siendo su prevalencia estimada 24,6 casos de todas las formas clínicas de HA por 100000 nacimientos varones $(9,5$ casos de HA severa) y para la HB es 5 por 100000 nacimientos varones (1,5 casos de HB severa) (4).

La principal complicación del tratamiento es el desarrollo de inhibidores que, en el contexto de la hemofilia, se definen como alloanticuerpos de tipo IgG que neutralizan el factor infundido. Se observa con mayor frecuencia en la HA severa, alcanzando una incidencia acumulativa de $\sim 30 \%$ entre los pacientes con HA que no han sido tratados previamente o PUPs (Previously Untreated Patients). En el 79\% de los casos ocurre en los primeros $20 \mathrm{DE}$ (día de tratamiento o exposición al factor carente) y el resto antes de los $75 \mathrm{DE}$ (5).

En HA leve o moderada la incidencia de inhibidores es menor, situándose entre 5 a $10 \%$. En esta población de pacientes, los anticuerpos se desarrollan más tardíamente, a menudo luego de tratamientos intensivos y generalmente se manifiesta con cambios en el patrón se sangrados, similar al observado en la hemofilia adquirida, debido a reacción cruzada de los anticuerpos con el FVIII endógeno (6). En pacientes con HB severa se observan con menor frecuencia, con incidencia acumulativa que alcanza 9,3\% a los $75 \mathrm{DE}$, describiéndose en algunos pacientes reacciones alérgicas y/o anafilácticas con la exposición al FIX (7).

En relación con la etiopatogenia, se han implicado factores de riesgó genéticos y no genéticos o ambientales. En el primer grupo, los principales son el tipo de hemofilia, tipo de mutación del gen, la historia familiar de inhibidores, la raza o etnia y los polimorfismos en genes de respuesta inmune. Entre los factores no genéticos o potencialmente modificables, se destacan los relacionados al tratamiento, como la intensidad y duración del primer tratamiento y la clase de concentrado de factor de coagulación (CFC) utilizado (8).

En la HA, uno de los aspectos más controversiales se refiere a las diferencias en la inmunogenicidad entre los dos tipos de CFC, de origen plasmático o recombinante. En este sentido los resultados del primer estudio aleatorizado (SIPPET), realizado en pacientes previamente no tratados o mínimamente tratados, reportó una incidencia de inhibidor del 26,8\% (IC95\%: 18,4-35,2) con los CFC plasmáticos que contienen FVIII con FvW (Factor von Willebrand) y del 44,5\% (IC 95\%: 34,7-54,3) con diferentes productos recombinantes (9).

En este sentido, el análisis de la evolución de 154 PUPs-HA con FVIII < 2UI/dL, evaluados entre 2000-2013, en el Centro Nacional de Hemofilia del Banco Municipal de Caracas (CNH-BMS), confirma el hallazgo de alta frecuencia de inhibidores persistentes en nuestra población (45\%), siendo de alto título el 28,5\%. Las variables estadísticamente significativas resultaron ser la historia familiar de inhibidores, la edad y la intensidad del primer tratamiento. No se encontraron diferencias relacionadas al tipo de producto utilizado, CFC plasma derivado con bajo contenido de FVW o GFC recombinante de segunda generación (10).

La inmunogenicidad de los nuevos CFC de FVIII (CFC-FVIII) está por definirse. Para la fecha solo se tienen resultados parciales derivados del análisis preliminar de los estudios con Simoctocog alfa (11) y Efmoroctocog alfa (12), ambas moléculas producidas por células embrionarias de riñón humano (HEK293) transfectados con rFVIII. Teóricamente estas moléculas tienen la ventaja de

Vol. 62(1): 73 - 95, 2021 
asegurar modificaciones pots-tranlacionales similares a la del factor VIII humano. La relevancia del tipo de línea celular usado para producción de CFC recombinantes, ha sido discutido previamente a la luz de diferencias en inmunogenicidad de los concentrados de FVIII recombinantes de segunda y tercera generación (13).

Aun cuando se considera que no hay una evidencia clara y consistente sobre una diferencia en la incidencia de inhibidores entre las dos clases de productos, para la mayoría de los hematólogos tratantes de hemofilia, este es un aspecto para considerar en forma individualizada, al momento de iniciar la profilaxis en niños con HA severa.

Para definir el tratamiento a utilizar en el paciente con inhibidores se recomienda su detección temprana y su cuantificación en Unidades Bethesda (UB), por el método Bethesda o su modificación de Nijmegen (3), estudio que debe realizarse con mayor frecuencia en etapas iniciales del tratamiento, antes de procedimientos invasivos o cuando hay sospecha clínica. Según su valor se clasifican en inhibidor de bajo título, si no se eleva a $>5$ UB aun después de exposición al factor o de alto título $>5 \mathrm{UB}$, lo cual generalmente hace inefectivo el tratamiento de remplazo. Los pacientes con inhibidores persistentes tienen mayor tendencia a la artropatía, al desarrollo de complicaciones derivadas de las hemorragias y mayor mortalidad.

El manejo de una condición tan compleja como la hemofilia ha evolucionado significativamente, pero especialmente en las dos últimas décadas cuando el progreso terapéutico ha cambiado de manera radical el manejo de esta patología. Todos estos avances y sus potenciales limitaciones serán revisados a continuación.

\section{Bases del tratamiento actual de la hemofilia}

La visión moderna del tratamiento de la hemofilia y sus complicaciones parte del establecimiento de principios o recomenda- ciones definidas inicialmente por la Federación Mundial de la Hemofilia (FMH) y por la Organización Mundial de la Salud (OMS) en 1990 (14), posteriormente ampliadas y actualizadas por diversos organismos regionales y sociedades científicas con el interés de aplicar las mismas en otras poblaciones $(15,16)$. En la Tabla I, se señalan los principios fundamentales necesarios para garantizar la atención integral de la persona con hemofilia (PCH).

De lo antes expuesto, podemos inferir que el tratamiento moderno de la hemofilia se basa en dos aspectos fundamentales, el primero es el manejo del paciente por un equipo multidisciplinario, lo cual fomenta la salud integral a la vez que disminuye la morbilidad y mortalidad de esta población. En segundo lugar, la disponibilidad de tratamiento, generalmente con CFC seguros, que permitan el tratamiento oportuno en el hogar y especialmente la administración profiláctica, regular y prolongada, a fin de prevenir el sangrado y el desarrollo de la artropatía hemofílica.

Con los avances conseguidos en las técnicas de seguridad de los concentrados utilizados, el interés de la comunidad de hemofilia se ha dirigido a optimizar el tratamiento para evitar las complicaciones, iniciar la profilaxis en forma temprana, personalizar o individualizar los esquemas de profilaxis utilizando datos de farmacocinética (PK) y/o desenlaces clínicos, generalmente medidos como tasa anualizada de sangrado (ABR, annualized bleeding rate), y en mejorar la calidad de vida de las PCH (17).

La profilaxis en hemofilia consiste en la administración regular de productos terapéuticos con el objetivo de prevenir el sangrado, especialmente el articular, como potencial causa de artropatía y discapacidad. Se considera el tratamiento de elección para pacientes con fenotipo severo, lo cual incluye la hemofilia severa y algunas formas de hemofilia moderada con fenotipo severo. En este grupo de pacientes, no se recomienda el tratamiento episódico (al momento del san- 


\section{TABLA I}

PRINCIPIOS FUNDAMENTALES PARA LA ATENCIÓN INTEGRAL DE LAS PCH (3).

1. Establecimiento de un programa nacional de atención al PCH integrado al sistema de salud: Contempla la atención por equipo multidisciplinar, el establecimiento de red de centros de tratamiento, el diagnóstico de laboratorio, registro de pacientes y sus complicaciones y la disponibilidad de tratamiento seguro y efectivo.

2. Acceso a tratamiento con concentrados de factores de la coagulación, incluyendo los aǵentes tipo baipás para tratamiento de pacientes con inhibidores y posibilidad de aceeso a terapias emergentes.

3. Servicio de laboratorio especializado: Clasificación del tipo y severidad de la hemofilia, diagnóstico y cuantificación de inhibidores, diagnóstico genético del paciente y portadoras potenciales.

4. Educación y entrenamiento de personal especializado: Capacitación de personal del equipo de salud multidisciplinar, colaboración entre centros de tratamiento.

5. Desarrollo de la investigación clínica y epidemiológica.

6. Tratamiento de las emergencias: Capacitación del paciente, su núcleo familiar y el personal de salud sobre el manejo de las emergencias y su tratamiento adecuado.

7. Atención integral por equipo multidisciplinar y participación en organizaciones y empoderamiento sobre su condición.

8. Terapia de reemplazo administrada en forma regular (Profilaxis): En pacientes con hemofilia severa o moderada e iniciada antes de los 3 años, para prevenir complicaciones musculoesqueléticas.

9. Tratamiento de pacientes con inhibidores: Vigilancia sistemática de la complicación, erradicación de los inhibidores mediante ITI

10. Tratamiento de las complicaciones musculoesqueléticas: Prevención y tratamiento de complicaciones musculoesqueléticas. Participación en actividades deportivas.

11. Manejo de condiciones específicas y comorbilidades. Diaǵnóstico y atención de portadoras de hemofilia. Prevención y tratamiento de comorbilidades.

12. Evaluación de desenlaces: Evaluación de impacto de la condición y sus complicaciones, efectividad de la terapia hemostática. Calidad de vida y aspectos económicos.

PCH: Personas con hemofilia. ITI: Terapia de inducción de la inmunotolerancia.

grado) ya que esta modalidad, aun en dosis altas de factor, no altera la historia natural de la hemofilia, llevando al daño musculoesquelético y a otras complicaciones derivadas del sangrado (18).

La profilaxis con CFC, debe ser individualizada, tomando en consideración la frecuencia de sangrados, el daño articular existente y el comportamiento farmacocinético individual, especialmente en población pediátrica (19-21). Se recomienda sea iniciada tempranamente, antes de los 3 años y antes de producirse el daño articular, cuando se define como profilaxis primaria. Las dosis y frecuencia recomendadas pueden variar según el fenotipo del paciente, el tipo de agente hemostático a utilizar y a la posibilidad de acceso al tratamiento $(22,23)$.

Durante la profilaxis, aun es motivo de debate, el nivel valle óptimo o nivel mínimo de factor circulante alcanzado después de administrar una dosis de factor. Un nivel valle de $1 \%$ pudiera no ser suficiente para prevenir sangrados en pacientes con estilo de vida activo o en quienes ya presentan artropatía. Evaluaciones realizadas a largo plazo, más de 20 años en pacientes tratados con profilaxis primaria aun en altas dosis, ha per-

Vol. 62(1): 73 - 95, 2021 
mitido identificar cierto grado de artropatía, generalmente localizada en tobillos, en una minoría de pacientes (24). Basado en estos hallazgos se ha sugerido mantener un nivel valle superior, eercano al $12 \%$ de actividad de factor. Sin embargo, con los CFC disponibles, la frecuencia y la dosis utilizada serían significativamente mayores, limitando su aplicación por fallas en la adherencia y el elevado costo del tratamiento.

La adherencia al tratamiento profiláctico y su eficacia pueden ser afectados o limitados por el hecho de que los productos disponibles, plasma derivados o recombinantes, comparten propiedades farmacocinéticas similares, tienen una vida media $\left(\mathrm{t}^{1 / 2}\right)$ biológica corta y deben ser administrados por infusiones intravenosas frecuentes y en ocasiones mediante el uso de accesos venosos centrales con todas las complicaciones que esto implica (25).

En los últimos 20 años, la posibilidad de tratamiento de la PCH se ha ampliado de manera significativa con la incorporación al arsenal terapéutico de diferentes tipos de CFC, la mayoría de origen recombinante, obtenidos en nuevas líneas celulares o modificados, con el fin de extender la vida media del FVIII o del FIX y por el desarrollo de otros agentes hemostáticos diferentes a la terapia de remplazo.

Estos avances llevan a redefinir la profilaxis como la administración regular (vía endovenosa, subcutánea u otra por definirse) de un agente/agentes con el objetivo de mejorar el proceso de la hemostasia y efectivamente prevenir sangrados en $\mathrm{PCH}$, permitiéndoles llevar una vida activa con calidad de vida comparable a la de una persona sin hemofilia (26).

Concentrados de factores de coagulación con vida media extendida o con modificaciones en su estructura

En la Tabla II, se señalan las diferentes tecnologías utilizadas para mejorar las propiedades farmacocinéticas de los CFC necesarios para el tratamiento de ambos tipos de hemofilia (27). Los mayores avances se centran en el desarrollo de concentrados de vida media extendida (CFC-EHL por sus siglas en inglés), basados en la tecnología de fusiòn con el fragmento Fe de la IǵG1 o con albúmina recombinante y en el uso de Polietilenglicol. (Tablas III y IV). Para la monitorización en el laboratorio de la terapia de remplazo con CFC-EHL se recomienda el uso de ensayos validados para cada caso en particular debido a que los resultados de laboratorio pueden variar según se utilicen diferentes metodologías y reactivos (3).

\section{CFC con proteína de fusión-Fe}

La capacidad funcional del receptor Fe neonatal ( $\mathrm{FeRn})$ en prolongar la vida media de la $\operatorname{IgG}$, orientó a la producción por bioingeniería de nuevas proteínas mediante fusión a la región fragmento cristalizable (Fe) de la IgG. La presencia del dominio Fe incrementa significativamente la vida media plasmática de la proteína fusión y prolonga su actividad terapéutica por interacción con el receptor neonatal FeRn. Las proteínas que son internalizadas por las células endoteliales se unen al receptor Fe presente en el endosoma acidificado y son recicladas a la superficie a un $\mathrm{pH}$ neutral, evitando la degradación lisosomal de la IǵG y de la proteína.

La fusión de una forma monomérica de IǵG1-Fe al FIX, o al FVIII dominio B truncado, con excreción como forma dimérica de una molécula de Fe y una de la proteína coagulante, aumenta la t $1 \frac{1}{2}$ plasmática. Otras ventajas son la mejor solubilidad y estabilidad de la molécula acompañante y el facilitar los procesos de purificación (28).

Por esta técnica se desarrollaron los factores rFVIIIFe y rFIXFe, cuya seguridad y eficacia ha sido demostrada en varios estudios clínicos realizados en pacientes adultos y niños previamente tratados (PPT) con más de 50 DE (29-31).

Nuestra experiencia en el Centro Nacional de Hemofilia del Banco Municipal de Sangre de Caracas (CNH-BMS) con el uso de estos CFC-EHL ha sido excelente. El primer 
TABLA II

ESTRATEGIAS PARA DESARROLLAR NUEVOS TRATAMIENTOS EN HEMOFILIA.

Tecnología
Pegilación
Unión covalente a moléculas pegiiladas

Fusión del dominio Fe de la IgG

o de la albúmina a proteínas

Polisialilación. Conjugación de polímeros lineales de $\mathrm{N}$-acetilneuramínico

Polímero de proteínas XTEN

Péptido carboxi-terminal

Modificación de secuencia de aminoácidos

Aptámeros o anticuerpos específicos dirigidos a inhibidores naturales de la coagulación (antitrombina, inhibidor de la vía del factor tisular).

ARN de interferencia

Anticuerpos biespecíficos a FIXa y FX
Mecanismo de acción

Aumento de masa/peso molecular. Modificaciones que reducen la filtración glomerular, degradación proteolítica y aclaramiento por receptores específicos, todo lo cual resulta en prolongación de la vida media terminal de la proteína.

Unión al receptor Fe neonatal (FeRn) que se ubica en las células endoteliales y facilita el reciclaje de la proteína a la superficie celular para ser liberada a la circulación.

Método alterno a pegilación. Mejora estabilidad enzimática y disminuye la excreción renal por aumentar la masa molecular

Incorpora polipéptido no estructurado para extender la vida media. Utilizada para FVIII.

Fusión de péptido C-ter de gonadotrofina coriónica a proteínas

Mejora estabilidad. Usada en diseño de FVIII recombinante de una cadena

Mejorar generación de trombina por supresión de anticoagulación

Reducir producción de antitrombina

Mimetiza acción de FVIIIa. Uso en pacientes con o sin inhibidores.

Modificado de Peyvandi F, Garagiola I. (25).

análisis fue realizado en PPT, 221 con HA y 78 con $\mathrm{HB}$, en rango de edades de 1-79 años, quienes recibieron rFVIIIFe o rFIXFe como tratamiento episódico, en profilaxis, para la terapia de inducción de la inmunotolerancia (ITI) en HA o en cirugías, con excelentes resultados en cuanto eficacia y seguridad. El $90 \%$ de los pacientes con HA en profilaxis recibió la infusión una a dos veces a la semana mientras que en HB el réǵimen de profilaxis fue una infusión cada 7 a 10 días (32).

La eficacia de rFVIIIFe en ITI es actualmente evaluada en tres estudios, orientados a definir su eficacia como terapia de inicio, en un segundo intento de ITI o combinada con uso semanal de emicizumab. En PUPs mayores de 4 meses de edad, se evaluará la eficacia y seguridad de rFVIIIFe en profilaxis comparando con emicizumab semanal con el estudio NCT04303559 (33).

En general para profilaxis en $\mathrm{HB}$, con los CFC-IX-EHL, la dosis varía de $20 \mathrm{UI} / \mathrm{kg} /$ semanal, cada 10 días a $40 \mathrm{UI} / \mathrm{kg}$, o cada 2 semanas a $100 \mathrm{UI} / \mathrm{kg}$, suficiente para mantener nivel de FIX de $1 \mathrm{UI} / \mathrm{dl}$ en la mayoría de los pacientes adultos con HB (34). En niños con HB, la dosis más utilizada es 50-60 UI/ kg una vez por semana (35). La eficacia y seguridad de su uso luego de un mínimo de 5 años de tratamiento fue confirmada en el estudio B-YOND realizado en adultos y niños mayores de 12 años (36).

Vol. 62(1): 73 - 95, 2021 


\section{TABLA III}

CARACTERÍSTICAS DE LOS CONCENTRADOS DE FACTOR VIII MODIFICADOS O CON VIDA MEDIA EXTENDIDA APROBADOS PARA USO CLÍNICO

\begin{tabular}{|c|c|c|c|c|}
\hline $\begin{array}{l}\text { Concentrado } \\
\text { Nombre genérico }\end{array}$ & $\begin{array}{l}\text { Vida } \\
\text { Media } \\
\text { horas }\end{array}$ & $\begin{array}{l}\text { Línea } \\
\text { celular }\end{array}$ & Tecnología & Estudios clínicos \\
\hline $\begin{array}{l}\text { Elocta }{ }^{\circledR} / \text { Eloctate }{ }^{\circledR} \\
\text { Efmorocotocog alfa }\end{array}$ & 19 & $\begin{array}{l}\text { HEK } \\
293\end{array}$ & $\begin{array}{c}r \text { FVIII-Fe (FVIII-BDD) } \\
\text { Fusión al fraǵento Fe } \\
\text { de la IgG1 }\end{array}$ & $\begin{array}{l}\text { A-LONG }(29) \\
\text { Kid-A-Long } *(30) \\
\text { ASPIRE }(31)\end{array}$ \\
\hline $\begin{array}{l}\text { Adynovi } \AA_{\text {/Adynovate }}^{\circledR} \\
\text { Rurioctocog alfa pegol }\end{array}$ & $14,3-16$ & $\mathrm{CHO}$ & $\begin{array}{l}\text { FVIII cadena completa } \\
\text { Pegilación 20kDa }\end{array}$ & $\begin{array}{l}\text { PROLONG-ATE (42) } \\
\text { Estudio pediátrico* }(43)\end{array}$ \\
\hline $\begin{array}{l}\text { Jivi } \\
\text { Damoctocog alfa pegol }\end{array}$ & 18,7 & BHK & $\begin{array}{l}\text { FVIII-BDD-Pegilación } \\
\text { específica PEG 60kDa } \\
\text { en dominio A3 }\end{array}$ & $\begin{array}{l}\text { PROTECT (44) } \\
\text { Estudio pediátrico" (50) }\end{array}$ \\
\hline $\begin{array}{l}\text { Esperoct }{ }^{\circledR} \\
\text { Turoctocog alfa pegol }\end{array}$ & 19 & $\mathrm{CHO}$ & $\begin{array}{c}\text { FVIII-BDD } \\
\text { Pegilación específica } \\
\text { PEG 40kDa }\end{array}$ & $\begin{array}{l}\text { PATHFINDER }(46,47) \\
\text { Estudio pediátrico" }(48)\end{array}$ \\
\hline MODIFICADOS & & & & \\
\hline $\begin{array}{l}\text { Afstyla }{ }^{\circledR} \\
\text { Lonoctocog alfa }\end{array}$ & 14,5 & $\mathrm{CHO}$ & $\begin{array}{l}\text { FVIII-BDD de una sola } \\
\text { cadena con unión } \\
\text { covalente de cadena } \\
\text { pesada y liviana y mayor } \\
\text { afinidad por FVW }\end{array}$ & $\begin{array}{l}\text { AFFINITY (56) } \\
\text { Estudio pediátrico* } \\
\text { (57) }\end{array}$ \\
\hline $\begin{array}{l}\text { Nuwiq }{ }^{\circledR} \\
\text { Simoctocog alfa }\end{array}$ & $14,7-17$ & $\begin{array}{l}\text { HEK } \\
293\end{array}$ & $\begin{array}{l}\text { FVIII-BDD con } \\
\text { modificaciones en el } \\
\text { patrón de glicosilación } \\
\text { y sulfatación. Mayor } \\
\text { afinidad por FVW }\end{array}$ & $\begin{array}{c}\text { GENA (54) } \\
\text { Nupreviq * (55) } \\
\text { Nu-protect en PUPs (11) }\end{array}$ \\
\hline
\end{tabular}

FVIII-BDD: Factor VIII depletado del dominio B; FVW: Factor von Willebrand; HEK: Human Embrionic Kidney;CHO: Chinese Hamster Ovary; BHK Baby Hamster Kidney *Estudios pediátricos realizados en población de pacientes previamente tratados < 12 años; PUPs: Pacientes previamente no tratados con HA.

Recientemente se culminaron los estudios en PUPs, el PUPs A-Long en HA (12) y PUPs B-Long en HB (37). En el primero, el $31,1 \%$ de los PUPs desarrollaron un inhibidor, siendo en el $15,6 \%$ de alto título. Esta tasa de inhibidores se considera dentro del rango esperado para esta población de pacientes. Otro aspecto de gran interés, actualmente en estudio, es la posibilidad de su efecto inmunomodulador o a largo plazo en la salud ósea/ articular, mediante propiedades antiinflamatorias, aún por confirmar (38).

\section{CFC con fusión con albumina}

La albumina es una molécula estable y con vida media prolongada y mediante procesos de asociación, conjugáación o fusión genética a diferentes proteínas se ha utilizado para extender la vida media de las mismas. Este efecto es debido a su interacción con el receptor neonatal $\mathrm{Fe}$, mecanismo similar al descrito para IgG. Esta metodología se usó para la producción del FIX-FP, Albutrepenonacog alfa, aprobado para uso clínico en pacientes con HB, con excelentes resul- 


\section{TABLA IV \\ CARACTERÍSTICAS DE LOS CONCENTRADOS DE FACTOR IX CON VIDA MEDIA EXTENDIDA APROBADOS PARA USO CLÍNICO.}

\begin{tabular}{|c|c|c|c|c|}
\hline $\begin{array}{l}\text { Concentrado } \\
\text { Nombre genérico }\end{array}$ & $\begin{array}{l}\text { Vida media } \\
\text { horas }\end{array}$ & Línea celular & Mecanismo & Estudios clínicos \\
\hline $\begin{array}{l}\text { Alprolix }{ }^{\circledR}- \\
\text { rFIX-Fe } \\
\text { Eftrenonacog alfa }\end{array}$ & 82,1 & HEK & $\begin{array}{c}r \text { FIX- Fe } \\
\text { (Fusión al } \\
\text { fragento Fe de la } \\
\text { IgG1 }\end{array}$ & $\begin{array}{c}\text { B-LONG (31) } \\
\text { Kids-B-Long población } \\
\text { pediátrica (32). B-Yond (33) }\end{array}$ \\
\hline $\begin{array}{l}\text { Ildevion }{ }^{\circledR} \\
\text { Albutrepenacog alfa }\end{array}$ & 102 & $\mathrm{CHO}$ & $\begin{array}{l}\text { rFIX unido } \\
\text { a albúmina } \\
\text { recombinante }\end{array}$ & $\begin{array}{c}\text { PROLONG 9FP (39) } \\
\text { PROLONG 9FP em población } \\
\text { pediátrica }(40,41)\end{array}$ \\
\hline $\begin{array}{l}\text { Refixia }{ }^{\circledR} \\
\text { Nonacog } \beta \text { pegol }\end{array}$ & $70-93$ & $\mathrm{CHO}$ & rFIX peǵilado & $\begin{array}{c}\text { PARADIGM }(49,50) \\
\text { Población pediátrica }(51)\end{array}$ \\
\hline
\end{tabular}

HEK: Human Embrionic Kidney; CHO: Chinese Hamster Ovary.

tados en cuanto a eficacia y seguridad tanto en adultos como en niños y con seguimiento por más de 5 años. Las dosis recomendadas varían entre 35 a $50 \mathrm{UI} / \mathrm{kg}$ semanal a $75 \mathrm{UI} /$ kg cada 10 a 14 días (39-41).

\section{CFC pegilados}

La unión covalente de proteínas a polímeros de polietilenglicol (PEG) se realiza mediante diferentes procesos: al azar por unión a grupos épsilon amino de los residuos de lisina, específica por unión a residuos libres de cisteína o por bioingeniería. Las moléculas utilizadas varían en tamaño desde $20 \mathrm{kDa}$ a $60 \mathrm{kDa}$. Esta técnica se ha utilizado para desarrollar CFC-rFVIII y CFCrFIX (42-51).

Un aspecto aún por definirse es la potencial toxicidad de las moléculas pegiladas cuando son utilizadas a largo plazo, como sería la situación para la hemofilia. Con otras moléculas pegiladas, a nivel experimental en animales, se ha descrito toxicidad renal y formación de anticuerpos anti-PEG. En este sentido, en el estudio PROTECT VIII-Kids, ocho niños PPT $<12$ años, desarrollaron anticuerpos contra PEG y fueron retirados del estudio (52). A diferencia de la Food Drug Administration(FDA), en Europa la EMA ha restringido el uso de $\mathrm{CFC}$ pegilados para PPT mayores de 12 años.
Otros concentrados recombinantes de FVIII con modificaciones en su estructura molecular

Simoctocog alfa

Es un CFC-rFVIII producido en línea celular HEK sin fusión a otras proteínas humanas y utilizando medios de cultivo libre de proteínas humanas o de origen animal. Se describe, mayor sulfatación en el amino ácido (a.a.) Tirosina 1680 para facilitar su unión al FVW y otras modificaciones post-traslacionales que aseguran un patrón de glicosilación óptimo, similar al FVIII nativo. Estos cambios lo hacen diferente y potencialmente menos inmunogénico que los CFC producidos en otras líneas celulares (BHK o CHO) (53). En el estudio Nu-Protect, un total de 28 PUPs de 105 (26,7\%) desarrollaron inhibidores, siendo en $11(10,5 \%)$ de bajo título y en $17(16,2)$ de alto título $(11,54,55)$. Estos resultados sugieren baja inmunogenicidad, similar a FVIII plasmático, este aspecto está por definirse posteriormente.

\section{Lonoctocog alfa}

Es FrVIII-BDD recombinante de una sola cadena, la cadena pesada y liviana están unidas en forma covalente para mejorar la estabilidad intrínseca y su afinidad por FVW. Se produce en células de CHO y su uso está aprobado para el tratamiento de PPT con HA $(56,57)$. 


\section{Comentarios}

En el caso de los CFC-EHL de FIX se ha logrado extender la vida media entre 3 a 5 veces la de los FIX convencionales. En la práctica, esto se refleja en una menor frecuencia de tratamiento profiláctico, a una infusión endovenosa cada 7 a 21 días para pacientes con HB. Algunos de estos concentrados muestran mayor recuperación in vivo por menor distribución al espacio extravascular que el FIX estándar y por ende las dosis necesarias para profilaxis pueden ser menores. La eficacia global en la prevención del sangrado se ubica entre 96,7 a 97,2\%.

En los pacientes con HA, debido a que el FVIII circula unido al FVW y su aclaramiento es determinado por el nivel de este factor, con todos los CFC-EHL o modificados, el $t^{1 / 2}$ del factor infundido varía entre 18 a 19 horas, es decir $\sim 1,5$ veces el valor del FVIIIr estándar, con recuperación in vivo similar, esto se refleja en la práctica en una disminución limitada en la frecuencia de las infusiones para el tratamiento profiláctico, en la mayoría de los pacientes solo a dos veces por semana o cada 5 días.

\section{Concentrados de FVIII en desarrollo}

Para obviar la limitación observada en HA, actualmente está en fase de desarrollo un tipo de CFC-EHL producido mediante fusión de proteínas utilizando la tecnología XTEN. La misma consiste en la inserción de un polipéptido no estructurado (polímero de proteína XTEN), para estabilizar el FVIII sin necesidad de unión al FVW circulante endógeno (58).

El producto más avanzado es rFVIIIFeVWF-XTEN (BIVV001), proteína de fusión que consiste en el dominio D'D3 del FVW fusionado a rFVIIIFC y un polipéptido XTEN, que en esta molécula específica son dos, uno de 288 a. a. entre dominio A2 y A3 del FVIII y otro de 144 a.a entre dominio D’D3 y el Fc, confiriéndole a la molécula mejor solubilidad y reduciendo su depuración.

En los estudios de fase 1 y 2 , en PPT con HA, mayores de 18 años, se observó pro- longación de vida media del FVIII a $\sim 40$ horas según la dosis administrada, es decir 3-4 veces la vida media del FVIII plasmático, lo cual sugiere la posibilidad de uso semanal. Actualmente se inician los estudios en fase 3 con este nuevo concentrado administrado 1 vez a la semana por vía IV (59).

\section{Terapias emergentes o productos hemostáticos diferentes a la terapia de remplazo}

Por décadas, el objetivo del tratamiento de la hemofilia fue enfocado a mejorar la terapia de remplazo con el factor carente (Fig. 1), sin embargo, la tecnología recombinante y el conocimiento de los mecanismos moleculares de la hemostasia ha permitido el desarrollo de terapias innovadoras diferentes a la terapia de remplazo, cambiando ese paradigma. El uso de terapias innovadoras administradas por vías diferentes a la endovenosa y con una frecuencia menor de administración, ya es una realidad para pacientes con HA con o sin inhibidores.

\section{Emicizumab}

Es un anticuerpo quimérico biespecífico que se une a FIX/FIXa y a FX/FXa, mimetizando la función de cofactor del FVIII en pacientes con HA, con o sin inhibidores. Debido a su afinidad a factor IXa y a factor FX, promueve la activación de este último y la formación de la tenasa, necesaria para generar trombina y garantizar la hemostasia (60). Actualmente se sugiere el término "terapia de sustitución" para definir el uso de emicizumab en hemofilia $(3,61)$.

Muestra un perfil farmacocinético linear y vida media de 4 a 5 semanas en voluntarios sanos. Inicialmente, manteniendo la concentración plasmática entre 45 a 50 $\mu \hat{g} / \mathrm{mL}$, se calculó una equivalencia a 13 a $15 \%$ de actividad de FVIII. Recientemente el desarrollo de un modelo murino ha calculado que su efecto hemostático es equivalente a una concentración de FVIII plasmático de $9 \mathrm{UI} / \mathrm{dL}$ (9\%) y que el uso adicional de FVIII, aporta un efecto prohemostático adicional $(62,63)$. 


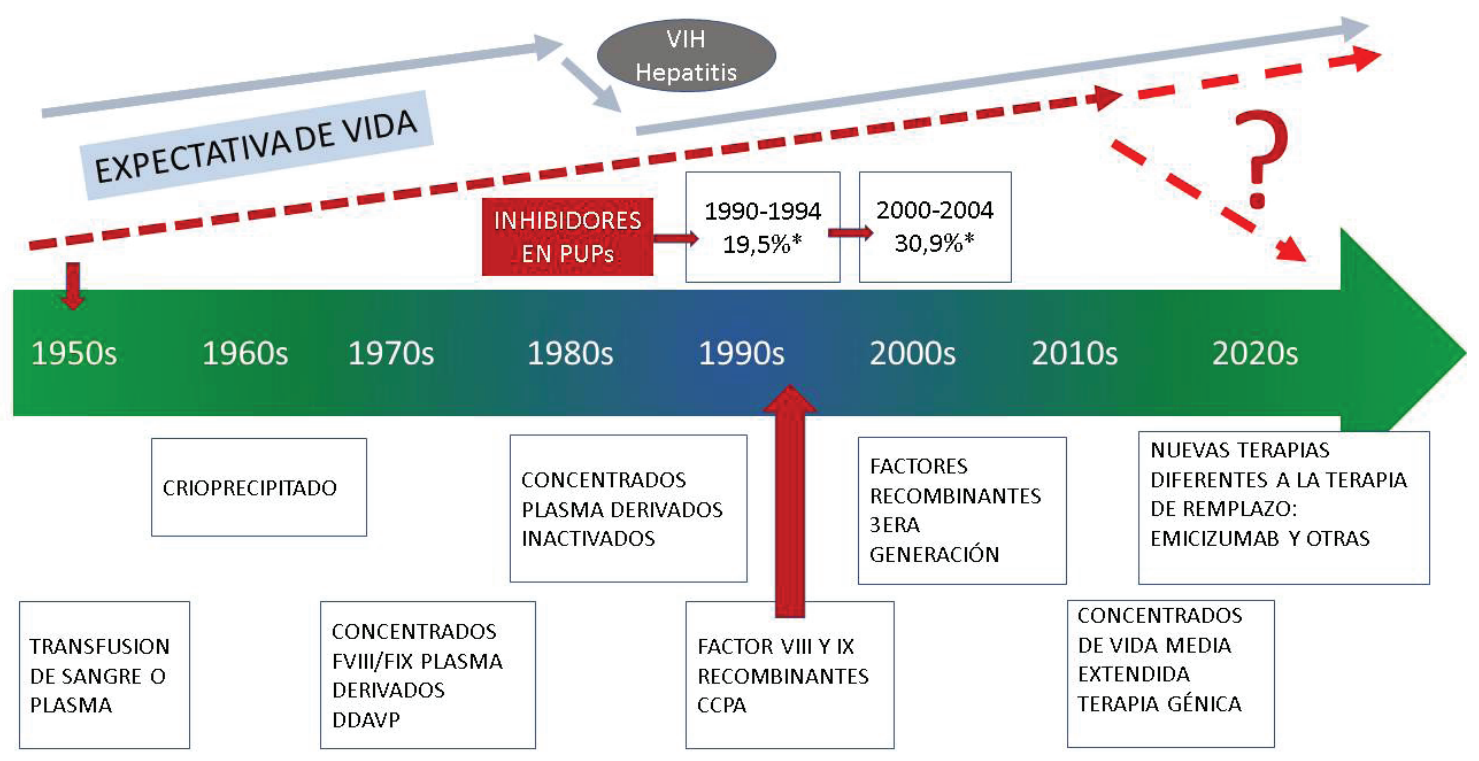

Fig. 1. Progresos en el tratamiento de la hemofilia. Los avances más signnificativos se inician en la década de 1970s con el desarrollo de los primeros concentrados plasmáticos, liofilizados de FVIII, de FIX en la forma de concentrados de complejo protrombínico así como por el uso potencial de desmopresina (DDAVP). En la década de 1980 se clonaron los genes de FVIII/IX, pero este período fue marcado por la tragedia de la infección por VIH además de las hepatitis virales. En 1990 se inicia la aplicación de técnicas de inactivación/eliminación viral y la producción de factores recombinantes de 1era generación. Se desarrollan los aǵentes baipás para el tratamiento de los pacientes con inhibidores. Para el 2000 , los esfuerzos se centran mejorar el desarrollo de los factores recombinantes, eliminando proteínas de oriǵen animal o humano en el proceso de producción. Para la última década, la biotecnología permite el desarrollo de concentrados de factores con vida media extendida, de terapias innovadoras diferentes a la terapia de remplazo y grandes progresos en la terapia génica. En los últimos años la atención se ha centrado en la principal complicación del tratamiento de la hemofilia, el desarrollo de inhibidores, su etiopatogenia, prevención y erradicación y las opciones de tratamiento para este grupo de pacientes.

La eficacia y seguridad en profilaxis de sangrado con emicizumab fue evaluada en los ensayos clínicos HAVEN, inicialmente en pacientes con inhibidores, HAVEN 1 y 2 $(64,65)$, comentados en la siguiente sección y posteriormente en HA sin inhibidores, con el estudio HAVEN 3 (66), que evaluó su uso en profilaxis de sangrado en PPT $>12$ años sin inhibidores, observándose reducción significativa en la frecuencia de hemorragias durante su uso.

El estudio HAVEN 4 fue diseñado para evaluar la farmacocinética y farmacodinamia del producto, en dosis cada 4 semanas en PPT >12 años, con o sin inhibidores, con esta frecuencia demostró eficacia equivalente a la descrita para la dosis semanal o de cada dos semanas previamente evaluadas (67). El estudio HAVEN 7, actualmente en curso, evaluará su uso en PUPs con HA sin inhibidores y el estudio HOHOEMI confirmó su eficacia y seguridad en niños menores de 12 años, la mayoría de ellos PPT (68).

A diferencia de la terapia convencional, emicizumab puede ser administrado vía subcutánea (VSG) con biodisponibilidad de $100 \%$. La profilaxis se inicia con periodo de inducción con $3 \mathrm{mg} / \mathrm{kg} / \mathrm{semana}$ por $4 \mathrm{se}$ - 
manas VSC, seguida de dosis de $1,5 \mathrm{mg} / \mathrm{kg}$ semanal, $3 \mathrm{mg} / \mathrm{kg}$ cada 2 ó $6 \mathrm{mg} / \mathrm{kg}$ cada 4 semanas. Durante su uso, los sangrados agudos o los procedimientos invasivos deben ser tratados con CFC-FVIII o con agentes baipás, preferiblemente factor VII activado recombinante, en el caso de pacientes con inhibidores. En este grupo de pacientes, no se recomienda el uso de concentrados de complejo protrombina activados (CCPa) ya que se han descrito episodios de trombosis venosa o de microangiopatía trombótica relacionados a su uso (3).

En pacientes HA sin inhibidores, no existe consenso en las recomendaciones sobre el momento de iniciar el tratamiento profiláctico con emicizumab. La posibilidad de utilizarlo para evitar sangrados graves en SNC en el recién nacidos con HA grave o las hemartrosis en el lactante, generalmente después de los seis meses de edad, amerita la realización de estudios prospectivos diseñados para tal fin. Emicizumab difiere del FVIII en términos de afinidad, regulación, topología y actividad funcional sobre FIXa, de tal forma que se desconoce el impacto sobre la salud especialmente ósea y articular a largo plazo $(69,70)$.

Por otra parte, existen aspectos relacionados a su uso en la práctica clínica que aún están por resolver (71). Los más evaluados son: 1.- Monitorización de la terapia: El uso de emicizumab afecta los resultados de las pruebas convencionales como PTT (Tiempo de tromboplastina parcial) y la determinación de FVIII por métodos en una etapa o cromogénicos con excepción de los que usan reactivos de origen bovino. Dentro de las posibilidades en estudio se describe uso de calibradores de emicizumab diluído o uso de pruebas globales como la tromboelastografía rotacional (ROTEM). 2.- Inmunogenicidad: En los estudios HAVEN, dos de 400 pacientes, desarrollaron anticuerpos dirigidos a emicizumab. En estos casos se describe, prolongación de la prueba de PTT como reflejo de la falla del efecto hemostático del agente (72).
Su uso fue aprobado por agencias regulatorias (FDA y EMA) y en más de 50 países, para la profilaxis de los episodios hemorrágicos en pacientes con HA con o sin inhibidores. Posterior a su aprobación, se han reportado casos fatales en pacientes tratados con emicizumab, situación actualmente en estudio para definir su posible relación con el medicamento. En la mayoría de los casos complicados se confirma el uso de CCPa como aǵente baipás para tratar algún episodio hemorrágico (73).

\section{Otros agentes hemostáticos}

Las estrategias en investigación más avanzadas se basan en el concepto de restaurar la hemostasia inhibiendo la acción de los anticoagulantes naturales, es decir de la antitrombina, del inhibidor de la vía del factor tisular (TFPI, por sus siglas en inglés) o de la proteína $\mathrm{C}$ activada (en etapa inicial de desarrollo).

\section{Fitusiran (ALN-AT3)}

Es un ARN de interferencia silenciador de la producción de antitrombina. Se une específicamente al ARN mensajero de la antitrombina suprimiendo su producción en el hígado y aumentando la generación de trombina. Tiene la ventaja de la administración subcutánea, acción prolongada con dosificación mensual y uso potencial en ambos tipos de hemofilia con o sin inhibidores (74). En los estudios de fase 1 se confirmó la capacidad de reducir los niveles de antitrombina hasta en un 70 a $89 \%$, en sujetos sanos y en pacientes con HA o HB sin inhibidores, mejorando la generación de trombina a niveles normales.

El estudio fue suspendido por varios meses debido a la observación de eventos trombóticos graves. Actualmente los estudios OLE y ATLAS se han reiniciado para continuar análisis de seguridad y eficacia. Durante su uso los sangrados agudos deben ser tratados con dosis bajas de CFC o agentes baipás para minimizar el riesgo de trombosis. 


\section{Anti-TFPI}

El inhibidor de la vía del factor tisular (TFPI) es una proteasa de serina, inhibidor natural de la fase inicial de la coagulación, regula la coagulación inducida por la expresión de factor tisular e inactiva al factor Xa $\mathrm{y}$ al complejo factor VIIa-factor tisular. $\mathrm{Su}$ bloqueo extiende la fase inicial de la coagulación, permite mayor generación de factor Xa y compensa parcialmente la deficiente generación de este factor y de trombina característica de la hemofilia.

Se han desarrollado varias moléculas con esta función, pero debido a efectos adversos serios principalmente de tipo trombótico, algunos estudios clínicos se han suspendido. El principal agente en desarrollo es el concizumab (mAb 2021), anticuerpo monoclonal con alta afinidad que se administra por VSC, dosis diaria y uso potencial en pacientes con HA o HB, con o sin inhibidores. Evaluado en los estudios Explorer 1 al 8 (fase 3), suspendidos en marzo 2020 por la observación de complicaciones trombóticas no fatales y reiniciados recientemente con cambios en la evaluación de seguridad $(75,76)$. Existen otros dos anticuerpos monoclonales anti-TFPI en investigación, el más avanzado es Marstacimab, actualmente iniciando los estudios de fase 2 (77).

Avances en el tratamiento de los pacientes con inhibidores persistentes

Para el tratamiento del episodio agudo en pacientes con $>5$ UB se recomienda el uso de los llamados agentes baipás, el Factor VII activado recombinante (rFVIIa) para pacientes con HA y HB o el concentrado de complejo protrombina activado (CCPa) o FEIBA (Factor Eight Inhibitor Bypassing Agent), generalmente utilizado en HA, ya que por su contenido de factor IX no se recomienda su administración en pacientes HB con inhibidores e historia de reacción alérgi ica a concentrados de FIX.

El rFVIIa tiene la desventaja de requerir mayor frecuencia de dosis debido a su vida media corta ( $\sim 2$ horas), similar a la del FVII plasmático. Para mejorar este aspecto, inicialmente se diseñaron variantes con mayor actividad biológica. Sin embargo, estas moléculas fallaron en los estudios clínicos debido a efectos adversos de tipo inmune (78). Actualmente está en curso un estudio fase 3 de una nueva variante de rFVIIa con sustitución de 4 a.a, marzeptacog alfa, que muestra mayor actividad catalítica, siete veces mayor que el rFVIIa (eptacog alfa) y prolongada vida media $\sim 9,5$ horas, lo cual permitiría su uso por VSC (79).

Recientemente se aprobó para uso clínico una variante de rFVIIa, de segunda generación, eptacog beta, (FVIIa recombinante-jncw), secretado en la leche de conejas transgénicas, con diferencias en la interacción con el EPCR (receptor endotelial para $\mathrm{PC})$ que pudieran otorgarle ventajas farmacocinéticas (80).

A fin de erradicar el inhibidor en los pacientes con HA con inhibidor de alto título, se recomienda la terapia de inducción de la inmunotolerancia o ITI (ITI, por sus siglas en inglés). Esta terapia se basa en la exposición al factor carente de forma continuada con el objetivo de conseguir desensibilización del sistema inmune y permitir de muevo el tratamiento con terapia de remplazo. Actualmente se recomienda iniciarla tan pronto se detecta el inhibidor de alto título $>5$ UB persistente (81).

Existen diversos esquemas terapéuticos basados en diferentes dosis, frecuencia de las infusiones y tipo de CFG a utilizar. Los criterios de respuesta fueron definidos inicialmente por un grupo de expertos y los resultados de estudios clínicos multicéntricos. La mayoría de los pacientes con HA con inhibidores llegar a ser "inmunotolerantes", con tasa de erradicación entre 51-76\% luego de 1 a 3 años de tratamiento $(82,83)$.

Para la profilaxis de episodios hemorrágicos en pacientes con inhibidores recientemente se aprobó el uso de emicizumab basado en los estudios HAVEN 1 y 2 , con excelentes resultados en cuanto a eficacia. Se observó reducción en la tasa anualizada de

Vol. 62(1): 73 - 95, 2021 
sanǵrados comparándola con el ǵrupo con tratamiento episódico o con profilaxis con aǵentes baipás $(p<0,001)$. Entre 63-90\% de los pacientes en profilaxis no presentaron sangrados frente a un $6 \%$ en los pacientes sin profilaxis $(64,65)$.

En el estudio HAVEN 1 se comunicaron cinco eventos adversos graves de tipo trombótico incluyendo microangiopatía trombótica posiblemente asociados al uso concomitante de CCPa en dosis mayores a $100 \mathrm{UI} / \mathrm{kg} /$ día por más de 24 horas. Actualmente se recomienda en caso de sangrado el uso de uso preferente de FVIII si el título de inhibidor es bajo o rFVIIa a dosis máxima inicial de $90 \mu \mathrm{g} /$ $\mathrm{kg} /$ día. Solo si este agente no está disponible utilizar CCPa a la menor dosis ( $~ 50 \mathrm{UI} / \mathrm{kg})$ o aquella que permita controlar el sangrado. En estos casos se recomienda la hospitalización bajo estricta supervisión médica.

Aún está por definirse el momento de iniciar el uso de emicizumab, antes, durante o posterior a la ITI y esta decisión debe ser individualizada tomando en consideración la edad del paciente, la posibilidad de acceso venoso, el fracaso de ITI anteriores y la disponibilidad de tratamiento. El esquema más recomendado es el uso profilaxis con emicizumab asociado a ITI en dosis de FVIII a 50 $\mathrm{UI} / \mathrm{kg}$ tres veces por semana (84).

\section{Terapia génica}

El objetivo de la terapia génica (TG) sería lograr la cura de la hemofilia y de esta manera conseguir que los pacientes no dependan de otro tipo de terapia, especialmente de la terapia de remplazo regular por vía endovenosa. De ser exitosa, debería garantizar la expresión endógena del factor de coagulación y mantener un nivel circulante de factor estable y duradero. Actualmente más del $75 \%$ de las $\mathrm{PCH}$ a nivel mundial no tiene acceso a tratamiento seguro, por lo que la TG potencialmente pudiera ser una intervención que modifique el tratamiento de la hemofilia a nivel mundial.

La HA y HB son enfermedades monogénicas, sus genes han sido clonados, los incrementos leves o moderados de su nivel circulante mejoran significativamente la tendencia hemorrágica y su nivel plasmático puede ser determinado por diferentes técnicas en el laboratorio (85).

Se han utilizado diferentes estrategias para la TG de células somáticas. En hemofilia, todos los estudios actuales en fase 3, implican la transferencia genética de un vector viral, actualmente de tipo adenovirus asociado (AAV) recombinante, administrado por vía endovenosa (Tabla V). El AAV silvestre es un parvovirus no patógeno, con buen perfil de seguridad, que induce inmunogenicidad innata mínima, y se integra al endosoma y no al genoma celular. Existen varios serotipos y hasta la fecha se han utilizado vectores naturales rAAV, (AAV2, AAV5 y AAV8) y otros diseñados por bioingeniería (rAAV-Spark200, rAVV-Spark 100, rAVVrh-10 o el AAVS3), basados en serotipos naturales.

Los insertos transgénicos varían en tamaño según su ADN complementario (ADNc), para el factor IX es $\sim 1,3$ kilobases y para FVIII sin el dominio $\mathrm{B}$ es de $\sim 4,7$ kilobases. Hay además diferencias en la naturaleza del transgén, en HB se ha utilizado el factor IX Padua, que incorpora una mutación con ganancia de función que aumenta la actividad del factor entre 5 a 10 veces. La inclusión de un promotor híbrido hepático (HSP) o de un codón de optimización asociado al gen terapeútico se ha utilizado para mejorar la expresión hepática.

Los criterios actuales de inclusión y exclusión en los estudios de TG por AAV dirigida a hígado son estrictos (85). Son candidatos a TG: Varones $>18$ años con HA severa, FVIII $<1 \mathrm{UI} / \mathrm{dL}$ o HB con FIX $<2$ UI/ $\mathrm{dL}$, sin inhibidores, con más de $150 \mathrm{DE}$, en profilaxis o con un determinado número de sangrados anuales (variable según el estudio) que requieran tratamiento. Los criterios de exclusión incluyen inmunidad preexistente a cápside de $\mathrm{AAV}$ ( 60\% de las $\mathrm{PCH})$, disfunción hepática, hepatitis B si el antígeno de superficie es positivo, hepatitis C si el ARN viral es positivo, mientras que la condición VIH positivo no es siempre un criterio de exclusión. 
TABLA V

TERAPIA GÉNICA PARA HEMOFILIA A Y B. ESTUDIOS CLÍNICOS EN FASE 3 UTILIZANDO AAV DIRIGIDA A HÍGADO.

\begin{tabular}{lccc}
\hline Nombre & $\begin{array}{c}\text { Tipo de } \\
\text { hemofilia }\end{array}$ & $\begin{array}{c}\text { Serotivo AAV } \\
\text { (transgen) }\end{array}$ & $\begin{array}{c}\text { Identificación } \\
\text { y esponsor }\end{array}$ \\
\hline $\begin{array}{l}\text { Valoctocogene } \\
\text { roxaparvovec } \\
\text { (SPK-8011) }\end{array}$ & HA & AAV5 (FVIII-BDD) & $\begin{array}{c}\text { NCT03370913 } \\
\text { Biomarin }\end{array}$ \\
$\begin{array}{l}\text { Etranacogene } \\
\text { dezaparvovec }\end{array}$ & HB & Cápside modificada, similar a AAV8 & NCT03432520 \\
$\begin{array}{l}\text { Fidanacogene } \\
\text { elaparvovec }\end{array}$ & HB & FVIII-BDD & Spark Therapeutics \\
AAV5 (FIX Padua) & Cápside modificada similar a AAV8 & uniQure \\
Spark 100 (FIX Padua) & NCT03861273 \\
\hline
\end{tabular}

Modificado de Pipe S (85). FVIII-BDD: FVIII depletado del dominio B.

\section{Hemofilia A}

En 2017, se publicaron los primeros resultados prometedores para HA, utilizando AAV5-hFVIII-SQ (valactogene roxaparvovec). Un año después de la infusión, el nivel de FVIII se mantuvo entre $19-164 \%$ media de $77 \%$, con disminución de la tasa de sangrados.

El seguimiento hasta por 3 años de 15 adultos con HAS luego de recibir una infusión con diferentes dosis de vector, confirma la variabilidad de la respuesta individual en parte relacionada a dosis recibida. Se observó reducción en la tasa de sangrados anualizada y cese del uso profiláctico de FVIII en los participantes que recibieron dosis de $4 \times 10^{13}$ $\mathrm{vg} / \mathrm{kg}$ o $6 \times 10^{13} \mathrm{vg} / \mathrm{kg}$. Los niveles de factor alcanzaron los de la hemofilia leve en la mayoría de los pacientes. Actualmente se están reclutando pacientes para la fase 3 (86).

\section{Hemofilia B:}

El tamaño más pequeño de la secuencia del ADNe complementario del FIX permitió identificar diversos vectores para transferir el ADNc del FIX dentro de células, facilitando inicialmente el desarrollo de la terapia en HB. Los estudios pioneros utilizaron el serotipo AAV2 pero la respuesta inmune humoral y celular bloqueaba la transducción limitando la expresión del gen. El primer estudio con resultados exitosos utilizó serotipo AAV8. Luego de casi 10 años de observación alǵunos pacientes continúan con expresión del transgén, con niveles de FIX bajos entre 2 a $5 \%(87)$.

Otros estudios en HB, han utilizado la variante con ganancia de función Factor IX-Padua. Los más avanzados son el estudio SPK-9001, actualmente en fase 3. Durante el estudio fase 2 los pacientes alcanzaron un nivel de FIX plasmático entre 14,3-76,8\% durante el período de observación de 52 semanas. El uso de esta variante permite el uso de dosis de vector menores con menor riesgo de reacción inmune (88). Un segundo estudio, utiliza un vector AAV5 (FIX Padua), en fase 2 los pacientes alcanzaron niveles de FIX $\sim 40 \%$ con ausencia de sangrados durante el período de observación (89).

A la fecha más de 50 pacientes con HB han sido tratados con varios serotipos de vectores AAV (AAV5, AAV8 y AAVr10), se ha logrado expresión de FIX entre 1,9 a $>40 \%$, pero en la mayoría de los pacientes es menor a $10 \%$ de actividad y con duración variable. En el 31\% de los pacientes, se observó elevación de enzimas hepáticas asociada a disminución de la expresión transitoria en los niveles de FIX (90). 


\section{Aspectos por definir}

Si bien la TG para hemofilia es una estrategia promisoria, están por definirse los aspectos relacionados a seguridad, costo y durabilidad de esta. No hay dudas que la TG utilizando vectores $\mathrm{AAV}$ ha sido exitosa en términos de aumento de los niveles de factor y disminución de los requerimientos de terapia de remplazo, pero aun es un tratamiento en etapa de investigación.

En todos los estudios clínicos, se observa una amplia variabilidad interindividual de la respuesta terapéutica, parcialmente explicada por diferencias en la respuesta inmune. Hay muchas interrogantes que preocupan a la comunidad de hemofilia (91), especialmente relacionadas a la seguridad del procedimiento a corto y largo plazo.

En todos los estudios clínicos, se observa amplia variabilidad interindividual de la respuesta terapéutica, parcialmente explicada por diferencias en la respuesta inmune. En etapas tempranas, la mayoría de los pacientes presenta elevación de las enzimas hepáticas, asintomática y que responde al tratamiento con esteroides. Su etiología no está bien definida y se ha relacionado al efecto de linfocitos $\mathrm{T}$ citotóxicos frente a la cápside del vector. Se desconoce si a largo plazo se observe toxicidad hepática, especialmente en pacientes con infección por virus de hepatitis C previa.

Por definirse, la durabilidad de la respuesta a largo plazo y la posibilidad de un segundo intento de TG, cuando el desarrollo de anticuerpos anti-AAV pudiera limitar tratamientos similares a futuro. Otro tema de gran interés es la posibilidad de utilizar la TG en niños recién diagnosticados, ya que en esta población de pacientes la división activa de hepatocitos no garantizaría la expresión persistente de un vector no integrado como lo es un AAV. Otros aspectos a considerar son el riesgo potencial de mutagenesis insercional, de genotoxicidad o de cáncer a futuro.

Para mejorar los beneficios de la TG, se evalúan otras estrategias que incluyen la técnica de edición de genes para reparación genética, empleando enzimas tipo nucleasas Zine fingers (ZFBs) o CRISP-CAS y el uso de vectores lentivirales con integración genómica estable.

El pasado mes de aǵosto, la FDA luego de la revisión de los estudios de fase 2 y 3 , recomendó extender por dos años la observación de los pacientes del estudio fase 3 (NCT03370913), con Valoctocogene roxaparvovec en HA, con el objetivo de evaluar la duración del efecto utilizando la tasa anualizada de sangrados y obtener más datos sobre seguridad de la terapia (93). Decisión similar adoptó la aǵencia europea de medicamentos. (EMA).

\section{CONCLUSIONES}

La comunidad de hemofilia dispone en la actualidad de un rango amplio de posibilidades terapéuticas que pueden facilitar la individualización del tratamiento. La aplicación de biotecnología en la producción de nuevos factores de la coagulación recombinantes con vida media prolongada facilita los regímenes de profilaxis, al reducir la frecuencia de las dosis y extender sus beneficios. Por otra parte, la incorporación de terapias diferentes a la terapia de remplazo, administradas por vía subcutánea con frecuencia menor ha cambiado el paradigma del tratamiento y recientemente el avance en la terapia génica ha generado expectativas como potencial cura para la condición.

En la práctica, el objetivo fundamental debe ser disminuir o prevenir los sangrados y sus consecuencias. Sin embargó, aún hay aspectos por definir. Los riesgos deben ser evaluados con cada producto ya que son diferentes, la farmacovigilancia debe ser continua y estricta, especialmente enfocada a la formación de anticuerpos y a la toxicidad potencial de los medicamentos utilizados en población pediátrica y por tiempo prolongado. Con las nuevas terapias, se desconocen las consecuencias a largo plazo sobre la salud osteoarticular, el riesgo de complicacio- 
nes trombóticas reflejo del delicado balance del sistema hemostático y los riesgoos a largo plazo de la terapia génica.

La mayoría de estas opciones avanzadas son una realidad para países desarrollados, pero la mayoría de las PCH a nivel mundial no tiene acceso a forma alguna de tratamiento. Se estima que solo el $26 \%$ de las PCH están diaǵnosticadas lo cual constituye un reto y potencialmente una gran asignación de recursos de inversión para los sistemas de salud (93).

De lo antes expuesto podemos concluir que para la mayoría de las PCH a nivel mundial, lo fundamental es realizar el diagnóstico preciso de su condición, garantizar el acceso al tratamiento con CFC seguros, iniciar la profilaxis temprana en los pacientes con fenotipo severo bajo la supervisión de un equipo multidisciplinario, con la participación activa del paciente y su entorno familiar.

\section{REFERENCIAS}

1. Mannucei PM, Tuddenham EG. The hemophilias--from royal genes to gene therapy. $\mathrm{N}$ Eng1 J Med 2001;344(23):1773-9.

2. Blanchette VS, Key NS, Ljung LR, MancoJohnson MJ, van den Berg HM, Srivastava $A$; Subcommittee on Factor VIII, Factor IX and Rare Coagulation Disorders of the Scientific and Standardization Committee of the International Society on Thrombosis and Hemostasis. Definitions in hemophilia: communication from the SSC of the ISTH. J Thromb Haemost 2014;12(11):1935-1939.

3. Srivastava A, Santagostino E, Dougall A, Kitchen S, Sutherland M, Pipe SW, Careao M, Mahlangu J, Ragni MV, Windyǵa J, Llinás A, Goddard NJ, Mohan R, Poonnoose PM, Feldman BM, Lewis SZ, van den Berg HM, Pierce GF; WFH Guidelines for the Management of Hemophilia panelists and co-authors. WFH Guidelines for the Management of Hemophilia, 3rd edition. Haemophilia. 2020 Aug 3. doi: 10.1111/ hae.14046.
4. Iorio A, Stonebraker JS, Chambost H, Makris M, Coffin D, Herr C, Germini F; Data and Demographics Committee of the World Federation of Hemophilia. Establishing the prevalence and prevalence at birth of hemophilia in males: a meta-analytic approach using national registries. Ann Intern Med 2019;171(8):540-546.

5. van den Berg HM, Fischer K, Carcao M, Chambost H, Kenet G, Kurnik K, Königs C, Male C, Santagostino E, Ljung R; PedNet Study Group. Timing of inhibitor development in more than 1000 previously untreated patients with severe hemophilia A. Blood 2019;134(3):317-320.

6. Ljung R, Auerswald G, Benson G, Dolan G, Duffy A, Hermans C, Jiménez-Yuste V, Lambert T, Morfini M, Zupančić-Šalek S, Santagostino E. Inhibitors in haemophilia A and B: Management of bleeds, inhibitor eradication and strategies for difficult-to-treat patients. Eur J Haematol 2019;102(2):111-122.

7. Male C, Andersson NG, Rafowicz A, Liesner R, Kurnik K, Fischer K, Platokouki H, Santagostino E, Chambost H, Nolan B, Königs C, Kenet G, Ljung R, van den Berg $\mathrm{M}$; PedNet study group. Inhibitor incidence in an unselected cohort of previously untreated patients with severe haemophilia B: a PedNet study. Haematologica 2020 Jan 9:haematol.2019.239160. doi: 10.3324/ haematol.2019.239160.

8. Gouw SC, van den Berg HM, Fischer K, Auerswald G, Careao M, Chalmers E, Chambost H, Kurnik K, Liesner R, Petrini P, Platokouki H, Altisent C, Oldenburg J, Nolan B, Garrido RP, Mancuso ME, Rafowiez A, Williams M, Clausen N, Middelburg RA, Ljung $R$, van der Bom JG; PedNet and Research of Determinants of INhibitor development (RODIN) Study Group. Intensity of factor VIII treatment and inhibitor development in children with severe hemophilia A: the RODIN study. Blood 2013;121(20):4046-4055.

9. Peyvandi F, Mannucei PM, Garagiola I, ElBeshlawy A, Elalfy M, Ramanan V, Eshghi P, Hanagavadi S, Varadarajan R, Karimi M, Manglani MV, Ross C, Young G, Seth T, Apte S, Nayak DM, Santagostino E, Mancuso ME, Sandoval Gonzalez AC, Mahlangu

Vol. 62(1): 73 - 95, 2021 
JN, Bonanad Boix S, Cerqueira M, Ewing NP, Male C, Owaidah T, Soto Arellano V, Kobrinsky NL, Majumdar S, Perez Garrido R, Sachdeva A, Simpson M, Thomas M, Zanon E, Antmen B, Kavakli K, Manco-Johnson MJ, Martinez M, Marzouka E, Mazzucconi MG, Neme D, Palomo Bravo A, Paredes Aguilera R, Prezotti A, Schmitt K, Wicklund BM, Zulfikar B, Rosendaal FR. A randomized trial of Factor VIII and neutralizing antibodies in hemophilia A. New Enǵl J Med 2016;374(21):2054-2064.

10. Ruiz-Saez A, Boadas A, Echenagucia $M$, Castro-Mendez J. Risk factors associatedd with high-titre inhibitors development in previously untreated hemophilia A patients (PUPS-HA) born between 2000 and 2013: a single center experience. WFH 2016 Congress Abstracts, Orlando, Florida. Haemophilia 2016; 22 Suppl 4 P65

11. Liesner RJ, Abashidze M, Aleinikova $\mathrm{O}, \mathrm{Al}$ tisent C, Belletrutti MJ, Borel-Derlon A, Careao M, Chambost H, Chan AKC, Dubey L, Ducore J, Fouzia NA, Gattens M, Gruel Y, Guillet B, Kavardakova N, El Khorassani M, Klukowska A, Lambert T, Lohade S, Sigaud M, Turea V, Wu JKM, Vdovin V, Pavlova $A$, Jansen $M$, Belyanskaya $L$, Walter O, Knaub S, Neufeld EJ. Immunogenicity, efficacy and safety of Nuwiq ${ }^{\circledR}$ (human-cl rhFVIII) in previously untreated patients with severe haemophilia A-Interim results from the NuProtect Study. Haemophilia 2018;24(2):211-220.

12. Königs C, Ozelo MC, Dunn A, Kulkarni R, Nolan B, Brown SA. Final Results of PUPs A-LONG Study: Evaluating Safety and Efficacy of rFVIIIFe in Previously Untreated Patients with Haemophilia A [abstract]. Res Pract Thromb Haemost. 2020; 4 (Suppl1). https://abstracts.isth.org/abstract/finalresults-of-pups-a-long-study-evaluatingsafety-and-efficacy-of-rfviiife-in-previouslyuntreated-patients-with-haemophilia-a/. Accessed September 4, 2020.

13. Lai J, Hough C, Tarrant J, Lillicrap D. Biological considerations of plasma-derived and recombinant factor VIII immunogenicity. Blood $2017 ; 129(24): 3147-3154$.

14. WHO Hereditary Diseases Programme. Report of a Joint WHO/WFH Meeting on the Possibilities for the Prevention and Con- trol of Haemophilia, Geneva, 26-28 March 1990. Geneva Switzerland: World Health Orhanization; 1990. https://apps.who.int/ iris/handle/10665/60986. Accessed 3 de septiembre de 2020

15. Colvin BT, Astermark J, Fischer K, Gringeri A, Lassila R, Schramm W, Thomas A, Ingerslev $\mathbf{J}$; Inter Disciplinary Working Group. European principles of haemophilia care. Haemophilia 2008;14(2):361-374.

16. Boadas A, Ozelo MC, Solano M, Berges A, Ruiz-Saez A, Linares A, Lamas JL, Aparicio R, Aversa L, Baques A, Estrada A, Herrejon M, Mancia A, Nieves-Paulino R, Pinto I, Prezoti A, Soto V, Ugalde D. Haemophilia care in Latin America: assessment and perspectives. Haemophilia 2018;24(6):e395-e401.

17. Fischer K, Collins PW, Ozelo MC, Srivastava A, Young G, Blanchette VS. When and how to start prophylaxis in boys with severe hemophilia without inhibitors: communication from the SSC of the ISTH. J Thromb Haemost 2016;14(5):1105-1109.

18. Poonnoose P, Carneiro JDA, Cruickshank AL, El Ekiaby M, Perez Bianco RP, Ozelo MC, De Bosch N, Baghaipour M, Tien SL, Chuansumrit A, D'Amico EA, van Zyl A, Sabour A, Candela M, Ricciardi JBS, RuizSàez A, Ravanbod R, Lam JCL, Jaovisidha S, Kavitha ML, Gibikote S, Shyamkumar N, Srivastava A; MUSFIH Study group. Episodic replacement of clotting factor concentrates does not prevent bleeding or musculoskeletal damage - the MUSFIH study. Haemophilia 2017;23(4):538-546.

19. Swystun LL, Ogiwara K, Rawley O, Brown C, Georgeseu I, Hopman W, Labarque V, Male C, Thom K, Blanchette VS, Careao MD, Lillicrap D. Genetic determinants of VWF clearance and FVIII binding modify FVIII pharmacokinetics in pediatric hemophilia A patients. Blood 2019;134(11):880891.

20. Collins PW, Fischer K, Morfini M, Blanchette VS, Björkman S; International Prophylaxis Study Group Pharmacokinetics Expert Working Group. Implications of coagulation factor VIII and IX pharmacokinetics in the prophylactic treatment of haemophilia. Haemophilia 2011;17(1):2-10. 
21. Iorio A, Blanchette V, Blatny J, Collins P, Fischer K, Neufeld E. Estimating and interpreting the pharmacokinetic profiles of individual patients with hemophilia A or B using a population pharmacokinetic approach: communication from the SSC of the ISTH. J Thromb Haemost 2017;15(12):2461-2465.

22. Ozelo MC, Villaça PR, Pérez-Bianco R, Candela M, Garcia-Chavez J, MorenoRodriguez B, Rodrigues MB, RodriguezGreceo I, Solano MH, Chumpitaz G, Morales-Gana MM, Ruiz-Sáez A. Musculoskeletal evaluation in severe haemophilia A patients from Latin America. Haemophilia 2014;20(1):e63-70.

23. Gouider E, Jouini L, Achour M, Elmahmoudi H, Zahra K, Saied W, Meddeb B. Low dose prophylaxis in Tunisian children with haemophilia. Haemophilia 2017;23(1):7781.

24. Oldenburg J. Optimal treatment strategies for hemophilia: achievements and limitations of current prophylactic regimens. Blood 2015;125(13):2038-2044.

25. Buckley B, Dreyfus J, Prasad M, Gayle J, Kendter J, Hall E 2nd. Burden of illness and costs among paediatric haemophilia patients with and without central venous access devices treated in US hospitals. Haemophilia 2018;24(3):e93-e102

26. Carcao M, Lambert T, Leissinger C, Escuriola-Ettingshausen C, Santagostino E, Aledort L; International Prophylaxis Study Group (IPSG). Prophylaxis re-visited: The potential impact of novel factor and non-factor therapies on prophylaxis. Haemophilia 2018;24(6):845-848.

27. Peyvandi F, Garagiola I. Treatment of hemophilia in the near future. Semin Thromb Hemost 2015;41(8):838-848.

28. Powell JS. Lasting power of new clotting proteins. Hematology Am Soc Hematol Educ Program 2014(1):355-363.

29. Mahlangu J, Powell JS, Ragni MV, Chowdary P, Josephson NC, Pabinger I, Hanabusa H, Gupta N, Kulkarni R, Fogarty P, Perry D, Shapiro A, Pasi KJ, Apte S, Nestorov I, Jiang H, Li S, Neelakantan S, Cristiano LM, Goyal J, Sommer JM, Dumont JA, Dodd N, Nugent K, Viğliani G, Luk A, Brennan A, Pierce GF; A-LONG Investiga- tors. Phase 3 study of recombinant factor VIII Fe fusion protein in severe hemophilia A. Blood 2014;123(3):317-325.

30. Young G, Mahlangu J, Kulkarni R, Nolan B, Liesner R, Pasi J, Barnes C, Neelakantan S, Gambino G, Cristiano LM, Pieree GF, Allen G. Recombinant factor VIII Fe fusion protein for the prevention and treatment of bleeding in children with severe hemophilia A. J Thromb Haemost 2015(6):967-977.

31. Nolan B, Mahlangu J, Perry D, Young G, Liesner R, Konkle B, Rangarajan S, Brown S, Hanabusa H, Pasi KJ, Pabinger I, Jackson S, Cristiano LM, Li X, Pierce GF, Allen G. Long-term safety and efficacy of recombinant factor VIII Fe fusion protein (rFVIII$\mathrm{Fc}$ ) in subjects with haemophilia A. Haemophilia 2016;22(1):72-80.

32. Ruiz-Saez A, Boadas A, Echenagucia M. Use of extended half-life rFVIIIFe or rFIXFe in previously treated patients with haemophilia A or B. A single centre experience. Haemophilia 2019,25, S1 p50. $12^{\text {th }}$ Annual Congress of the European Association for Haemophilia and Allied Disorders, 2019. Prague Czech Republic.

33. https://www.clinicaltrials.gov/et2/show/ NCT04303559

34. Powell JS, Pasi KJ, Ragni MV, Ozelo MC, Valentino LA, Mahlangu JN, Josephson NC, Perry D, Manco-Johnson MJ, Apte S, Baker RI, Chan GC, Novitzky N, Wong RS, Krassova S, Allen G, Jiang H, Innes A, Li S, Cristiano LM, Goyal J, Sommer JM, Dumont JA, Nugent K, Vighliani G, Brennan A, Luk A, Pierce GF; B-LONG Investigators. Phase 3 study of recombinant factor IX Fe fusion protein in hemophilia B. N Enǵl J Med 2013;369(24):2313-2323.

35. Fischer K, Kulkarni R, Nolan B, Mahlangu J, Rangarajan S, Gambino G, Diao L, Ramirez-Santiago A, Pieree GF, Allen G. Recombinant factor IX Fe fusion protein in children with haemophilia B (Kids BLONG): results from a multicentre, nonrandomised phase 3 study. The Lancet Haematol 2017.; 4(2), e75-e82.

36. Pasi KJ, Fischer K, Ragni M, Kulkarni R, Ozelo MC, Mahlangu J, Shapiro A, P'Ng S, Chambost H, Nolan B, Bennett C, Matsushita T, Winding B, Fruebis $\mathbf{J}$, Yuan $\mathbf{H}$, Rudin D, Oldenburg J. Long-term safety 
and sustained efficacy for up to 5 years of treatment with recombinant factor IX Fe fusion protein in subjects with haemophilia B: Results from the B-YOND extension study. Haemophilia 2020;June 4. doi: 10.1111/ hae.14036.

37. Nolan B, Klukowska A, Shapiro A, Rauch A, Recht M, Ragni M. Final Results of PUPs B-LONG Study: Evaluating Safety and Efficacy of rFIXFe in Previously Untreated Patients with Haemophilia B [abstract]. Res Pract Thromb Haemost 2020; 4 (Suppl 1). https://abstracts.isth.org/abstract/finalresults-of-pups-b-long-study-evaluatingsafety-and-efficacy-of-rfixfe-in-previouslyuntreated-patients-with-haemophilia-b/. Accessed September 3, 2020.

38. Meeks SL, Lacroix-Desmazes S. Emerging benefits of $\mathrm{Fe}$ fusion technology in the context of recombinant factor VIII replacement therapy. Haemophilia 2020; Sep 3. doi: 10.1111/hae.14123.

39. Santagostino E, Martinowitz U, Lissitchkov T, Pan-Petesch B, Hanabusa H, Oldenburg J, Boggio L, Negrier C, Pabinger I, von Depka Prondzinski M, Altisent C, Castaman G, Yamamoto K, Álvarez-Roman MT, Voigt C, Blackman N, Jacobs I; PROLONG-9FP Investigators Study Group. Long-acting recombinant coagulation factor IX albumin fusion protein (rIX-FP) in hemophilia $B$ : results of a phase 3 trial. Blood 2016;127(14):1761-1769.

40. Kenet G, Chambost H, Male C, Lambert T, Halimeh S, Chernova T, Mancuso ME, Curtin J, Voigt C, Li Y, Jacobs I, Santagostino E; PROLONG-9FP Investigator Study Group. Long-acting recombinant fusion protein linking coagulation factor IX with albumin (rIX-FP) in children. Results of a phase 3 trial. Thromb Haemost 2016;116(4):659-668.

41. Kenet G, Chambost H, Male C, Halimeh S, Lambert T, Li Y, Seifert W, Santagostino E. Long-term safety and efficacy of recombinant Coagulation Factor IX Albumin Fusion Protein (rIX-FP) in previously treated pediatric patients with Hemophilia B: results from a Phase 3b Extension Study. Thromb Haemost 2020;120(4):599-606.

42. Konkle BA, Stasyshyn O, Chowdary P, Bevan DH, Mant T, Shima M, Engl W, Dyck-
Jones J, Fuerlinger M, Patrone L, Ewenstein B, Abbuehl B. Peǵylated, full-length, recombinant factor VIII for prophylactic and on-demand treatment of severe hemophilia A. Blood 2015;126(9):1078-1085.

43. Mullins ES, Stasyshyn O, Alvarez-Román MT, Osman D, Liesner R, Enǵl W, Sharkhawy M, Abbuehl BE. Extended half-life pegylated, full-length recombinant factor VIII for prophylaxis in children with severe haemophilia A. Haemophilia 2017;23(2):238-246.

44. Reding MT, Ng HJ, Poulsen LH, Eyster ME, Pabinger I, Shin HJ, Walsch R, Lederman M, Wang M, Hardtke M, Michaels LA. Safety and efficacy of BAY 94-9027, a prolonged-half-life factor VIII. J Thromb Haemost 2017;15(3):411-419.

45. Lalezari S, Reding MT, Pabinger I, Holme PA, Negrier C, Chalasani P, Shin HJ, Wang M, Tseneklidou-Stoeter D, Maas Enriquez M. BAY 94-9027 prophylaxis is efficacious and well tolerated for up to $>5$ years with extended dosing intervals: PROTECT VIII extension interim results. Haemophilia 2019;25(6):1011-1019.

46. Giangrande $P$, Andreeva T, Chowdary $P$, Ehrenforth S, Hanabusa H, Leebeek FW, Lentz SR, Nemes L, Poulsen LH, Santagostino E, You CW, Clausen WH, Jönsson PG, Oldenburg J; Pathfinder ${ }^{\mathrm{TM}} 2$ Investigators. Clinical evaluation of glycoPEGylated recombinant FVIII: Efficacy and safety in severe haemophilia A. Thromb Haemost 2017; $117(2): 252-261$.

47. Curry N, Albayrak C, Escobar M, Andre Holme P, Kearney S, Klamroth R, Misgav M, Négrier C, Wheeler A, Santagostino E, Shima M, Landorph A, Tønder SM, Lentz SR. Once-weekly prophylaxis with golycoPEGylated recombinant factor VIII (N8-GP) in severe haemophilia A: Safety and efficacy results from pathfinder 2 (randomized phase III trial). Haemophilia 2019;25(3):373-381.

48. Meunier S, Alamelu J, Ehrenforth S, Hanabusa H, Abdul Karim F, Kavakli K, Khodaie M, Staber J, Stasyshyn O, Yee DL, Rageliene L. Safety and efficacy of a ǵlycoPEGylated rFVIII (turoctocog alpha pegol, N8-GP) in paediatric patients with severe haemophilia A. Thromb Haemost 2017;117(9):1705-1713. 
49. Negrier C, Knobe K, Tiede A, Giangrande P, Møss J. Enhanced pharmacokinetic properties of a glycoPEGylated recombinant factor IX: a first human dose trial in patients with hemophilia B. Blood 2011;118(10):2695-2701.

50. Collins PW, Young G, Knobe K, Karim FA, Angehaisuksiri P, Banner C, Gürsel T, Mahlangu J, Matsushita T, Mauser-Bunschoten EP, Oldenburg $\mathbf{J}$, Walsh CE, Negrier C; paradigm 2 Investigators. Recombinant long-acting glycoPEGylated factor IX in hemophilia B: a multinational randomized phase 3 trial. Blood 2014;124(26):38803886.

51. Carcao M, Zak M, Abdul Karim F, Hanabusa H, Kearney S, Lu MY, Persson P, Rangarajan S, Santagostino E. Nonacog beta pegol in previously treated children with hemophilia B: results from an international open-label phase 3 trial. J Thromb Haemost 2016;14(8):1521-1529.

52. Santagostino E, Kenet G, Fischer K, Biss T, Ahuja S, Steele M. PROTECT VIII Kids: BAY 94-9027 (PEGylated Recombinant Factor VIII) safety and efficacy in previously treated children with severe haemophilia A. Haemophilia 2020;26(3):e55-e65. doi: 10.1111/hae.13963. Epub 2020 Mar 25.

53. Morfini M. Simoctocog alfa for the treatment of hemophilia A. Expert Opin Biol Ther 2017;17(12):1573-1580.

54. Tiede A, Oldenburg J, Lissitchkov T, Knaub S, Bichler J, Manco-Johnson MJ. Prophylaxis vs. on-demand treatment with Nuwiq( $\left({ }^{\circledR}\right)$ (Human-cl rhFVIII) in adults with severe haemophilia A. Haemophilia 2016;22(3):374-380.

55. Klukowska A, Szezepański T, Vdovin V, Knaub S, Bichler J, Jansen M, Dzhunova I, Liesner RJ. Long-term tolerability, immunogenicity and efficacy of Nuwiq ${ }^{\circledR}$ (humancl rhFVIII) in children with severe haemophilia A. Haemophilia 2018;24(4):595-603.

56. Mahlangu J, Kuliczkowski K, Karim FA, Stasyshyn O, Kosinova MV, Lepatan LM, Skotnicki A, Boggio LN, Klamroth R, Oldenburg J, Hellmann A, Santagostino E, Baker RI, Fischer K, Gill JC, P'Ng S, Chowdary P, Escobar MA, Khayat CD, Rusen L, Bensen-Kennedy D, Blackman N, Limsakun T, Veldman A, St Ledger K, Pa- binger I; AFFINITY Investigators. Efficacy and safety of rVIII-SingleChain: results of a phase $1 / 3$ multicenter clinical trial in severe hemophilia A. Blood 2016;128(5):630637.

57. Stasyshyn O, Djambas Khayat C, Iosava G, Ong J, Abdul Karim F, Fischer K, Veldman A, Blackman N, St Ledger K, Pabinger I. Safety, efficacy and pharmacokinetics of rVIII-SingleChain in children with severe hemophilia A: results of a multicenter clinical trial. J Thromb Haemost 2017;15(4):636644.

58. Seth Chhabra E, Liu T, Kulman J, Patarroyo-White $S$, Yang $B$, Lu Q, Drager D, Moore N, Liu J, Holthaus AM, Sommer JM, Ismail A, Rabinovich D, Liu Z, van der Flier A, Goodman A, Furcht C, Tie M, Carlage T, Mauldin R, Dobrowsky TM, Liu Z, Mercury O, Zhu L, Mei B, Schellenberger V, Jiang H, Pierce GF, Salas J, Peters R. BIVV001, a new class of factor VIII replacement for hemophilia A that is independent of von Willebrand factor in primates and mice. Blood 2020;135(17):1484-1496.

59. Konkle BA, Shapiro AD, Quon DV, Staber JM, Kulkarni R, Ragni MV, Chhabra ES, Poloskey S, Rice K, Katragadda S, Fruebis J, Benson CG. BIVV001 fusion protein as factor VIII replacement therapy for Hemophilia A. N Enǵl J Med 2020;383(11):1018-1027.

60. Kitazawa T, Shima M. Emicizumab, a humanized bispecific antibody to coagulation factors IXa and X with a factor VIIIa-cofactor activity. Int J Hematol 2020;111(1):2030.

61. Shima M, Sidonio RF Jr. Substitution therapy. Haemophilia. 2020; Jun 19. doi: 10.1111/hae.14072. Epub ahead of print.

62. Ferrière $\mathrm{S}$, Peyron I, Christophe OD, Kawecki C, Casari C, Muczynski V, Nathwani A, Kauskot A, Lenting PJ, Denis CV. A hemophilia A mouse model for the in vivo assessment of emicizumab function. Blood $2020 ; 136(6): 740-748$.

63. Shima M. Bispecific antibodies and advances in non-gene therapy options in hemophilia. Res Pract Thromb Haemost 2020; 28(4):446-454. doi: 10.1002/rth2.12337.

64. Oldenburg J, Mahlangu JN, Kim B, Schmitt C, Callaghan MU, Young G, Santagostino E, Kruse-Jarres R, Negrier C, Kessler 
C, Valente N, Asikanius E, Levy GG, Windyga $\mathbf{J}$, Shima M. Emicizumab prophylaxis in Hemophilia A with inhibitors. N Engl J Med 2017;377(9):809-818.

65. Young G, Liesner R, Chang T, Sidonio R, Oldenburĝ $\mathbf{J}$, Jiménez-Yuste $\mathrm{V}$, Mahlangu $\mathbf{J}$, Kruse-Jarres R, Wang M, Uguen M, Doral MY, Wright LY, Schmitt C, Levy GG, Shima M, Mancuso ME. A multicenter, open-label phase 3 study of emicizumab prophylaxis in children with hemophilia A with inhibitors. Blood 2019;134(24):2127-2138.

66. Mahlangu J, Oldenburg J, Paz-Priel I, Negrier C, Niggli M, Mancuso ME, Schmitt C, Jiménez-Yuste V, Kempton C, Dhalluin C, Callaghan MU, Bujan W, Shima M, Adamkewicz JI, Asikanius E, Levy GG, Kruse-Jarres R. Emicizumab prophylaxis in patients who have Hemophilia A without inhibitors. N Enǵ1 J Med 2018;379(9):811822.

67. Pipe SW, Shima M, Lehle M, Shapiro A, Chebon S, Fukutake K, Key NS, Portron A, Schmitt C, Podolak-Dawidziak M, Selak Bienz N, Hermans C, Campinha-Bacote A, Kiialainen A, Peerlinck K, Levy GG, Jiménez-Yuste $\mathbf{V}$. Efficacy, safety, and pharmacokinetics of emicizumab prophylaxis given every 4 weeks in people with haemophilia $\mathrm{A}$ (HAVEN 4): a multicentre, open-label, nonrandomised phase 3 study. Lancet Haematol 2019;6(6):e295-e305.

68. Shima M, Nogami K, Nagami S, Yoshida $\mathrm{S}$, Yoneyama K, Ishiguro A, Suzuki T, Taki M. A multicentre, open-label study of emicizumab given every 2 or 4 weeks in children with severe haemophilia A without inhibitors. Haemophilia 2019;25(6):979-987. doi: 10.1111/hae.13848. Epub 2019 Sep 12.

69. Lenting PJ, Denis GV, Christophe OD. Emicizumab, a bispecific antibody recognizing coagulation factors IX and X: how does it actually compare to factor VIII? Blood 2017; 130(23): 2463-2468.

70. Samuelson Bannow B, Recht M, Négrier C, Hermans C, Berntorp E, Eichler H, Mancuso ME, Klamroth R, O'Hara J, Santagostino E, Matsushita T, Kessler C. Factor VIII: Long-established role in haemophilia $\mathrm{A}$ and emerging evidence beyond haemostasis. Blood Rev 2019;35:43-50.
71. Shima M. Bispecific antibodies and advances in non-gene therapy options in Hemophilia. Res Pract Thromb Haemost 2020;4(4):446-454.

72. Harkins Druzgal C, Kizilocak H, Brown J, Sennett M, Young G. Neutralizing antidrug antibody to emicizumab in a patient with severe hemophilia A with inhibitors: New case with detailed laboratory evaluation [published online ahead of print, $2020 \mathrm{Jun}$ 16]. J Thromb Haemost. 2020;10.1111/ jth.14957. doi:10.1111/jth.14957

73. Makris M, Iorio A, Lenting PJ. Emicizumab and thrombosis: The story so far. J Thromb Haemost 2019;17(8):1269-1272.

74. Pasi KJ, Rangarajan S, Georgiev P, Mant T, Creagh MD, Lissitchkov T, Bevan D, Austin S, Hay CR, Hegemann I, Kazmi R, Chowdary P, Gercheva-Kyuchukova L, Mamonov V, Timofeeva M, Soh CH, Garg P, Vaishnaw A, Akine A, Sørensen B, Ragni MV. Targeting of antithrombin in Hemophilia A or B with RNAi therapy. N Engl J Med 2017;377(9):819-828.

75. Eichler H, Angehaisuksiri $P$, Kavakli K, Knoebl P, Windyǵa J, Jiménez-Yuste $\mathrm{V}$, Hyseni A, Friedrich U, Chowdary P. A randomized trial of safety, pharmacokinetics and pharmacodynamics of concizumab in people with hemophilia A. J Thromb Haemost. 2018;16(11):2184-2195.

76. Shapiro AD, Angchaisuksiri P, Astermark J, Benson G, Castaman G, Chowdary P, Eichler H, Jiménez-Yuste V, Kavakli K, Matsushita T, Poulsen LH, Wheeler AP, Young G, Zupancic-Salek S, Oldenburg J. Subcutaneous concizumab prophylaxis in hemophilia $\mathrm{A}$ and hemophilia $\mathrm{A} / \mathrm{B}$ with inhibitors: phase 2 trial results. Blood 2019;134(22):1973-1982.

77. Patel-Hett S, Martin EJ, Mohammed BM, Rakhe S, Sun P, Barrett JC, Nolte ME, Kuhn J, Pittman DD, Murphy JE, Brophy DF. Marstacimab, a tissue factor pathway inhibitor neutralizing antibody, improves coagulation parameters of ex vivo dosed haemophilic blood and plasmas. Haemophilia 2019;25(5):797-806.

78. Meeks SL \& Leissinger CA. The evolution of factor VIIa in the treatment of bleeding in haemophilia with inhibitors. Haemophilia 2019; 25(6), 911-918. 
79. Gruppo RA, Malan D, Kapocsi J, Nemes L, Hay CRM, Boggio L, Chowdary P, Tagariello G, von Drygalski A, Hua F, Scaramozza M, Arkin S. Marzeptacog alfa (activated) Study Group Investigators. Phase 1, singledose escalating study of marzeptacog alfa (activated), a recombinant factor VIIa variant, in patients with severe hemophilia. $\mathrm{J}$ Thromb Haemost 2018;16(10):1984-1993.

80. Biron-Andreani C, Schved JF. Eptacog beta: a novel recombinant human factor VIIa for the treatment of hemophilia A and $\mathrm{B}$ with inhibitors. Expert Rev Hematol 2019;12(1):21-28.

81. Ljung R, Auerswald G, Benson G, Dolan G, Duffy A, Hermans C, Jiménez-Yuste V, Lambert T, Morfini M, Zupančić-Šalek S, Santagostino E. Inhibitors in haemophilia A and B: Management of bleeds, inhibitor eradication and strategies for difficultto-treat patients. Eur J Haematol 2019; 102(2), 111-122.

82. Hay CR, DiMichele DM. International Immune Tolerance Study. The principal results of the International Immune Tolerance Study: a randomized dose comparison. Blood 2012;119(6):1335-1344.

83. Collins P, Chalmers E, Alamelu J, Hay C, Liesner R, Makris M, Mathias M, Payne J, Rangarajan S, Richards M, Talks K, Tunstall O, Williams M, Hart DP. First-line immune tolerance induction for children with severe haemophilia A: A protocol from the UK Haemophilia Centre Doctors' Organisation Inhibitor and Paediatric Working Parties. Haemophilia 2017;23(5):654-659.

84. Carcao M, Escuriola-Ettingshausen C, Santagostino E, Oldenburg $\mathbf{J}$, Liesner $\mathbf{R}$, Nolan B, Bátorová A, Haya S, Young G; Future of Immunotolerance Treatment Group. The changing face of immune tolerance induction in haemophilia A with the advent of emicizumab. Haemophilia 2019;25(4):676-684.

85. Pipe SW. Delivering on the promise of gene therapy for haemophilia. Haemophilia 2020 Jun 3. doi: 10.1111/hae.14027. Epub ahead of print.

86. Pasi KJ, Rangarajan S, Mitchell N, Lester W, Symington E, Madan B, Laffan M, Russell CB, Li M, Pierce GF, Wong WY. Multiyear Follow-up of AAV5-hFVIII-SQ Gene
Therapy for Hemophilia A. N Enǵl J Med 2020;382(1):29-40.

87. Nathwani AC, Reiss UM, Tuddenham EG, Rosales C, Chowdary P, McIntosh J, Della Peruta M, Lheriteau E, Patel N, Raj D, Riddell A, Pie J, Rangarajan S, Bevan D, Recht M, Shen YM, Halka KG, Basner-Tschakarjan E, Mingozzi F, High KA, Allay J, Kay MA, Ng CY, Zhou J, Cancio M, Morton CL, Gray JT, Srivastava D, Nienhuis AW, Davidoff AM. Long-term safety and efficacy of factor IX gene therapy in hemophilia B. N Enǵl J Med 2014;371(21):19942004.

88. George LA, Sullivan SK, Giermasz A, Rasko JEJ, Samelson-Jones BJ, Ducore J, Cuker A, Sullivan LM, Majumdar S, Teitel J, MeGuinn CE, Ragni MV, Luk AY, Hui D, Wright JF, Chen Y, Liu Y, Wachtel K, Winters A, Tiefenbacher S, Arruda VR, van der Loo JCM, Zelenaia O, Takefman D, Carr ME, Couto LB, Anguela XM, High KA. Hemophilia B gene therapy with a highspecific-avtivity Factor IX variant. N Engl J Med 2017;377(23):2215-2227.

89. Von Drygalski A, Giermasz A, Castaman G, Key NS, Lattimore S, Leebeek FWG, Miesbach W, Recht M, Long A, Gut R, Sawyer EK, Pipe SW. Etranacogene dezaparvovec (AMT-061 phase 2b): normal/near normal FIX activity and bleed cessation in hemophilia B. Blood Adv 2019;3(21):32413247.

90. Peyvandi F, Garagiola I. Clinical advances in gene therapy updates on clinical trials of gene therapy in haemophilia. Haemophilia 2019;25(5):738-746.

91. Pierce GF, Kaczmarek R, Noone D, O'Mahony B, Page D, Skinner MW. Gene therapy to cure haemophilia: Is robust scientific inquiry the missing factor? Haemophilia 2020 Sep 10. doi: 10.1111/ hae.14131. Epub ahead of print.

92. http://fdaaa.trialstracker.net/trial/ NCT03370913/

93. Stonebraker JS, Bolton-Maggs PHB, Brooker M, Evatt B, Iorio A, Makris M, O'Mahony B, Skinner MW, Coffin D, Pierce GF, Tootoonchian E. The World Federation of Hemophilia Annual Global Survey 1999. 2018. Haemophilia 2020;26(4):591-600. 